\title{
THE PROGRAM OF DEVELOPMENT OF PSYCHOLOGICAL PREPAREDNESS OF MILITARY SERVANTS OF AIRBORNE ASSAULT FORCES OF THE ARMED FORCES OF UKRAINE TO ACTIVITIES IN BATTLES
}

\author{
Andrii Kyrychenko \\ Adjunct at the Department of Moral and Psychological Ensuring the Activities, \\ National Defence University of Ukraine named after Ivan Cherniakhovskyi, Ukraine \\ e-mail: kyrychenkoav@ukr.net,orcid.org/0000-0002-1333-5980
}

\begin{abstract}
Summary
The article reveals the main tasks, purpose, content and structure of the program for the development of psychological readiness of servicemen of the Airborne Assault Forces of the Armed Forces of Ukraine to work in combat conditions "Born - to win" (hereinafter the program). The purpose of the program is not only to provide servicemen of Airborne Assault Forces with knowledge of psychological readiness, functioning of the body in extreme conditions and practical skills of self-regulation, but also to optimize the process of psychological readiness of paratroopers in combat. The main objectives of the program are: development of the motivational sphere, psychological readiness of servicemen for service and combat activities; acquaintance with the concepts of "psychological readiness", "psychological stability", "traumatic factors of modern combat", "preservation of mental health"; formation of a positive attitude to oneself, to the chosen profession, understanding and representation of servicemen's own actions on the battlefield, forecasting possible dangerous situations and making timely and correct decisions to overcome them; formation and development of skills and practical skills necessary for first aid, self-regulation and self-control of emotional state. Paratroopers enrich their professional experience, form and develop skills and abilities necessary to perform tasks on the battlefield in conditions of danger, uncertainty and suddenness, realize their own characteristics (know themselves), improve practical skills of first aid, self-regulation and self-control of emotional state. According to the results of the program is an effective tool for developing the psychological readiness of servicemen of the Airborne Assault Troops of the Armed Forces of Ukraine.
\end{abstract}

Keywords: psychological readiness; combat activities; motivation; development program; self-regulation.

\section{DOI: https://doi.org/10.23856/4714}

\section{Introduction}

The urgency of the development of the psychological readiness of the servicemen of the Airborne Assault Troops of the Armed Forces of Ukraine for activity in combat conditions becomes essential. Paratroopers, according to their specifics of professional activity, perform the most difficult combat tasks not only in the controlled territory, but also in the enemy's rear. So, for example, from July 19 to August 10, 2014 during a raid in the rear of the enemy units of the Airborne Assault Troops passed about $470 \mathrm{~km}$, of which $170 \mathrm{~km}$ behind the enemy. It was the longest raid on armored vehicles in recent military history, with fighting in militantcontrolled territory and the first clash with Russian paratroopers with the same symbols: blue berets and vests. During the operation, special attention was paid to the provision of food, fuel and ammunition. Of course, the paratroopers took all the necessary property, food and ammunition with them in the maximum number, as no one would deliver it to the enemy's rear. 
In these difficult conditions, each paratrooper relies on his own strength and friendly mutual assistance of colleagues, as well as to obtain trophies, both food, drinking water and Russian equipment, weapons and ammunition, which is identical in modification and can be used by our troops. The servicemen of the Airborne Assault Troops faced the most difficult situation, the evacuation of the wounded and killed, which is not possible in the rear, the enemy is everywhere 360 degrees (BBC News Ukraine, date of application 29.06.2021).

Thus, to solve the problem of psychological readiness of paratroopers to work in extreme conditions, a program was developed to develop the psychological readiness of servicemen of the Airborne Assault Forces of the Armed Forces of Ukraine to work in combat "Born - to win".

Analysis of the state of scientific development of this issue has shown the lack of sufficient scientific work to study the development of psychological readiness of servicemen of the Airborne Assault Troops of the Armed Forces of Ukraine. In general, related to the chosen research topic are the works of V.V. Stasiuk and O.A. Blinov.

Therefore, the urgency of the issue, its lack of development in modern psychology of theory and practice and the outlined contradictions lead to research in a particular direction.

The purpose of the article is to actualize the problem of developing the psychological readiness of paratroopers to work in extreme conditions. Coverage of the results of the development of the program for the development of psychological readiness of servicemen of the Airborne Assault Troops of the Armed Forces of Ukraine for activities in combat conditions "Born - to win".

\section{The contribution of the main research material}

To implement the defined tasks, the interrelated blocks of the program were based on the main components, such as: information-semantic, activity-reflexive, correctionaldevelopmental and diagnostic (Karamushki, 2005: 37).

The informational and semantic component enables the servicemen of the Assault Troops to understand the basic essence of psychological readiness for activity in combat conditions, the functioning of the organism in extreme conditions, the influence of motivation on success, etc. In the program, this component is implemented through selected methods of work: minilectures, group and individual exercises, group discussions and brainstorming.

Activity-reflexive component contributes to the formation and development of psychological readiness of paratroopers to perform assigned tasks, awareness (self-knowledge) of their own actions on the battlefield, overcoming the most difficult situations in danger, uncertainty and suddenness, enriching professional experience, self-regulation, providing the first help and self-control of emotional state, etc. This component is performed through practical exercises and training in the field with modeling of danger and the introduction of various elements inherent in the combat situation.

The correctional and developmental component allows to actualize motivation for self-improvement, positive attitude to oneself, to the chosen profession, realization of selfconfidence, desire for success, effective interaction, career growth, achievement of own life prospects and formation of reflective skills, etc. The selected component is implemented using the following forms and methods: group exercises and individual exercises, analysis of life and professional situations, group discussions, the method of incomplete sentences,

The diagnostic component of the program involves the analysis of the main criteria and established indicators of the level of psychological readiness of servicemen of the Assault Troops according to selected methods and a certain structure of components (motivational, cognitive-orientational, operational and emotional-volitional). 
The purpose of the program: is not only to provide servicemen of Airborne Assault Forces with knowledge of psychological readiness, functioning of the body in extreme conditions and practical skills of self-regulation, but also to optimize the development of psychological readiness of paratroopers to fight.

\section{Tasks of the program:}

1) development of the motivational sphere of servicemen for service and combat activities;

2) acquaintance with the concepts of "psychological readiness", "psychological stability", "traumatic factors of modern combat", "preservation of mental health";

3) formation of a positive attitude to oneself, to the chosen profession, understanding and representation of servicemen's own actions on the battlefield, forecasting possible dangerous situations and making timely and correct decisions to overcome them.

4) formation and development of skills and practical skills necessary for first aid, selfregulation and self-control of emotional state.

Target category: contract military servicemen serving in the Airborne Assault Troops of the Armed Forces of Ukraine.

Work tools for the program: projector, projector screen, laptop or computer, speakers, flipchart, markers, pens, workbooks, A4 paper, badges.

General structure of the program. The program "Born - to win" consists of an introduction, 4 interconnected blocks, summarizing and individual psychological counseling with a total duration of 21 hours. The main structure of the program is shown in table 1 .

Table 1

Structure of the program of development of psychological readiness of servicemen of the Airborne Assault Troops of the Armed Forces of Ukraine for activity in combat conditions "Born - to win"

\begin{tabular}{|c|l|c|}
\hline № & \multicolumn{1}{|c|}{ Basic activities } & $\begin{array}{l}\text { Quantity } \\
\text { by hours }\end{array}$ \\
\hline 1. & Introduction & 2 \\
\hline 2. & $\begin{array}{l}\text { Lesson 1.1 "Motivation and its effective impact on the combat activities of } \\
\text { servicemen of the Airborne Assault Troops". }\end{array}$ & 2 \\
\hline 3. & $\begin{array}{l}\text { Lesson 1.2 "Motivational strategy as an important determinant of successful } \\
\text { tasks on the battlefield". }\end{array}$ & 2 \\
\hline 4. & $\begin{array}{l}\text { Lesson 2.1. "Psychological readiness of Airborne Assault Troops as a major } \\
\text { factor in the successful implementation of combat tasks". }\end{array}$ & 2 \\
\hline 5. & $\begin{array}{l}\text { Lesson 2.2 "Modern combat and its impact on the mental processes of service- } \\
\text { men of the Airborne Assault Troops during the performance of assigned tasks". }\end{array}$ & 2 \\
\hline 6. & $\begin{array}{l}\text { Lesson 3.1 "There is such a profession - to defend the Motherland. Professional } \\
\text { activity of servicemen of the Airborne Assault Troops during the performance of } \\
\text { assigned tasks". }\end{array}$ & 2 \\
\hline 7. & $\begin{array}{l}\text { Lesson 3.2 "Practical actions of a soldier during combat missions in the rear of } \\
\text { the enemy". }\end{array}$ & 2 \\
\hline 8. & $\begin{array}{l}\text { Lesson 4.1 "Development of the emotional and volitional sphere of the Airborne } \\
\text { Assault Forces as a basis for the success of overcoming mental stress during } \\
\text { activities in special conditions". }\end{array}$ & 2 \\
\hline 9. & $\begin{array}{l}\text { Lesson 4.2 "Negative mental states and methods of self-regulation during } \\
\text { combat missions by servicemen of the Airborne Assault Troops". }\end{array}$ & 2 \\
\hline 10. & Summarizing the program \\
\hline 11. & Individual psychological counseling & 1 \\
\hline
\end{tabular}


Contents of the program.

Introduction.

1. Demonstration of a patriotic video.

Purpose: to evoke in the program participant's emotions that motivate a person to work and achieve a positive result and remind that the protection of the Fatherland, independence and territorial integrity of Ukraine, respect for its state symbols is a sacred duty of every citizen of Ukraine.

2. Self-presentation of the trainer (speaker), bringing to the participants the goals and objectives of the program.

Purpose: to present the facilitator (speaker) and to acquaint the participants with the purpose, tasks and planned activities of the training.

3. Exercise "Acquaintance"

Purpose: expanded acquaintance and rapprochement of participants.

4. Exercise "Waiting".

Purpose: to obtain important information from each participant about his expectations from the training.

5. Exercise "Basic rules of the group".

Purpose: to discuss and adopt the rules of the group, compliance with which during the lesson had a positive impact on the effectiveness of the work.

\section{Summing up}

\section{Motivational block}

Purpose: to form awareness of servicemen of the positive impact of motivation on achieving success and overcoming difficulties; development of motivation to successfully perform tasks in everyday and combat conditions.

Lesson 1.1 "Motivation and its effective impact on the combat activities of servicemen of the Airborne Assault Troops."

1. Introduction to the motivational block.

The course of execution. Proving the purpose, tasks, organization and interaction during work.

Information and semantic component:

2. Exercise "One old story" (Jackson, 2014: 21).

Purpose: interest of training participants, awareness of life values and the impact of motivation on success, the formation of a positive attitude towards themselves.

3. Exercise "Motivation for me is...".

Purpose: to encourage training participants to admire, analyze and develop knowledge about the phenomenon of motivation.

4. Mini-lecture: lecture "Motivation as one of the main factors of success"

Purpose: acquaintance with the concept of "motivation" and its role and place in the life of servicemen; formation of awareness of the positive impact of motivation on success.

Correction and development component:

5. Exercise "Steps to success"

Purpose: formation of the basic principles of definition of the purpose and ways of its achievement.

6. Summarizing the lesson.

Lesson 1.2 "Motivational strategy as an important determinant of successful tasks on the battlefield". 


\section{Information and semantic component:}

\section{Brainstorming on the topic: "Quotes about motivation".}

Purpose: to stimulate creative thinking, activity, reflection, self-belief, revealing the essence and use in later life of useful expressions of famous people.

2. Mini-lecture on the topic: "The role of motivation in performing assigned tasks".

Purpose: to reveal the features of the manifestation of motivation and its role in achieving individual and joint success of servicemen during activities in combat; development of motivation for the success of the combat mission.

\section{Exercise "Who am I in this world?"}

Purpose: to promote the development of skills of self-knowledge, thinking, reflection; fostering respect for oneself, colleagues and the chosen profession; awareness of self-importance and motivation in the course of performing assigned tasks.

\section{Exercise "Advertising agent".}

Purpose: to promote a positive image of military service, awareness of their own importance in the system of the Armed Forces of Ukraine and the development of the ability to interest and motivate others.

\section{Exercise "Through the eyes of other people".}

Purpose: to promote the development of skills of self-awareness, self-analysis, reflection; formation of self-esteem, awareness of the importance of the chosen profession and motivation to work in combat.

\section{Diagnostic component:}

\section{Psychological diagnosis.}

Purpose: to measure individual psychological differences in group members, to establish effective changes and qualitative characteristics of the impact of the motivational block of the program on servicemen.

\section{Summarizing the lesson.}

\section{Cognitive-orientation block.}

Purpose: to reveal the peculiarities of the formation and development of psychological readiness of servicemen for military service.

Lesson 2.1. "Psychological readiness of Airborne Assault Troops as a major factor in the successful completion of combat missions."

\section{Introduction to the cognitive-orientation block.}

Information and semantic component:

2. Brainstorming on the topic: "My psychological readiness"

Purpose: to unite and stimulate participants to active creative thinking, reflection.

3. Mini-lecture on the topic: "Psychological readiness of servicemen of the Assault Troops for extreme activities"

Purpose: acquaintance with the concept of "psychological readiness" and its significant impact on the course of the combat mission; formation of a conscious idea of their own actions on the battlefield and making timely and correct decisions.

\section{Correction and development component:}

\section{Exercise "My team"}

Purpose: to promote the development of skills of self-awareness, self-analysis, reflection; formation and development of self-esteem, authority, leadership qualities, willingness to cooperate, interact and trust in the team; demonstration of own individual-professional qualities necessary for formation of a fighting team. 
5. Group discussion on the topic: "Psychological readiness of servicemen: features and ways of its maintenance".

Purpose: development of practical thinking, self-improvement, reflection, use of own experience, representation of own actions on a battlefield, forecasting of possible dangerous situations and acceptance of timely correct decisions for their overcoming.

\section{Summarizing the lesson.}

Lesson 2.2 "Modern combat and its impact on the mental processes of servicemen of the Airborne Assault Troops during the performance of assigned tasks."

Information and semantic component:

1. Brainstorming: "Factors that complicate combat activities and affect the change of personal characteristics of the serviceman".

Purpose: formation of practical thinking, reflection, self-improvement, enrichment of own experience and understanding of own actions on the battlefield.

2. Mini-lecture on the topic: "Psychological resilience as one of the necessary properties of a serviceman of the Assault Troops to confront the challenges of modern combat"

Purpose: acquaintance with the concept of "psychological stability" and its impact on the course of the combat mission; formation of a conscious idea of their own actions on the battlefield and making timely and correct decisions.

Correction and development component:

3. The method of incomplete sentences "Reasons for reducing the level of psychological stability on the battlefield"

Purpose: development of skills of practical thinking, self-analysis, reflection, enrichment of own experience, awareness of personal behavior on the battlefield and the emergence of possible negative influences on the course of combat missions.

4. Group discussion on the topic: "Ways to restore psychological stability"

Purpose: formation of abilities and skills of practical thinking, self-analysis, reflection, interaction in collective, enrichment and use of own experience, motivation for success.

Diagnostic component:

5. Psychological diagnosis.

Purpose: to measure individual psychological differences in group members, to establish effective changes and qualitative characteristics of the impact of the motivational block of the program on servicemen.

6. Summarizing the lesson.

III. Operating block.

Purpose: formation and development of psychological readiness of servicemen of Airborne Assault Troops for activity in combat conditions.

Lesson 3.1 "There is such a profession - to defend the Motherland. Professional activity of servicemen of the Airborne Assault Troops during the performance of assigned tasks".

\section{Introduction to the operating unit.}

Information and semantic component:

2. Brainstorming on the topic: "Quotes that inspire and lead to victory"

Purpose: to stimulate creative thinking, activity, reflection, self-belief and victory in the battlefield, the discovery of the essence and use in later life of useful expressions of prominent military leaders and people. 


\section{Activity-reflexive component:}

\section{Exercise "Angry Crowd"}

Purpose: development of psychological readiness of servicemen to act in conditions of danger, uncertainty and suddenness; formation of skills and abilities of practical thinking, selfanalysis, reflection, interaction in collective, enrichment and use of own experience, motivation for success (Gritsevich, 2017: 35).

4. Exercise "Moving on the battlefield" (Chaplygina, 1975: 18).

Purpose: development of psychological readiness of servicemen to act in conditions of danger, uncertainty and suddenness; formation of skills and abilities to move on the battlefield, introspection, reflection, teamwork, enrichment and use of personal experience, motivation for success.

\section{Activity-reflexive component:}

5. Exercise "Reconnaissance in the rear of the enemy" (Chaplygina, 1975: 36).

Purpose: development of psychological readiness of servicemen to act in conditions of danger, uncertainty and suddenness; formation of skills and abilities during intelligence in the rear of the enemy, introspection, thinking, reflection, teamwork, enrichment and use of personal experience, motivation for success.

\section{Summarizing the lesson.}

\section{enemy." \\ Lesson 3.2 "Practical actions of a soldier during combat missions in the rear of the}

Activity-reflexive component:

\section{Exercise "Ambush"}

Purpose: development of psychological readiness of servicemen to act in conditions of danger, uncertainty and suddenness; formation of skills and abilities during the attack of the enemy, self-analysis, thinking, reflection, interaction in the team, enrichment and use of personal experience, motivation for success.

\section{Exercise "Assault on the building"}

Purpose: development of psychological readiness of servicemen to act in conditions of danger, uncertainty and suddenness; formation of skills during the storming of the building, introspection, thinking, reflection, interaction in the team, enrichment and use of personal experience, motivation for success.

\section{Exercise "Game duel"}

Purpose: development of psychological readiness of servicemen to act in conditions of danger, uncertainty and suddenness; formation of skills during the storming of the building, introspection, thinking, reflection, interaction in the team, enrichment and use of personal experience, motivation for success. (Armed Forces of Ukraine, 2021: 34).

4. Captive Exercise (Gritsevich, 2017: 334).

Purpose: development of psychological readiness of servicemen to act in conditions of danger, uncertainty and suddenness; formation of skills and abilities in situations close to reality, self-analysis, thinking, reflection, enrichment and use of one's own experience.

\section{Diagnostic component:}

\section{Psychological diagnosis.}

Purpose: to measure individual psychological differences in group members, to establish effective changes and qualitative characteristics of the impact of the operational unit of the program on servicemen.

\section{Summarizing the lesson.}


IV. Emotional and volitional block.

Purpose: to acquaint group members with the main signs and phases of stress, the formation and development of skills, practical skills needed for first aid, self-regulation and self-control of emotional state.

Lesson 3.1 "Development of the emotional and volitional sphere of the Airborne Assault Troops as a basis for the success of overcoming mental stress during activities in special conditions"

\section{Introduction to the emotional-volitional block.}

Information and semantic component:

2. Brainstorming on the topic: "Know yourself. Quotes about the disclosure of the inner strength of man, which stimulates and leads to victory.

Purpose: to stimulate creative thinking, activity, reflection, faith in yourself and in victory on the battlefield, the discovery of the essence and the use in later life of useful expressions of famous people.

Information and semantic component.

3. Mini-lecture on the topic: "Man is a weapon and its limitless possibilities"

Purpose: to reveal the professional capabilities of a serviceman as a soldier - a defender of the Motherland; formation and development of a conscious idea of one's own actions and psychological readiness to function in extreme conditions.

Correction and development component:

4. Exercise "Self-programming" (Shlachter, 2002: 12).

Purpose: formation of skills, practical skills necessary for self-regulation, self-control of emotional state and self-suggestion, aimed at increasing their own intellectual, physical and mental capabilities.

5. Exercise "My movie".

Purpose: awareness of their own capabilities, the formation of readiness to manage the emotional state.

Lesson 3.2. "Negative mental states and methods of self-regulation during combat missions by servicemen of the Airborne Assault Troops"

1. Mini-lecture on the topic: "Self-regulation of mental states of servicemen of the Airborne Assault Troops as one of the main conditions for the success of combat missions."

Purpose: to acquaint group members with the main signs and phases of stress and methods of self-regulation.

Exercise "Secret of breathing" (Memo to a serviceman in preparation for and in battle, 2015: 6).

Purpose: formation of skills and abilities necessary for self-regulation.

2. Exercise "Muscle relaxation" (Zoran Komar, 2017: 23).

Purpose: to develop skills and abilities to master the techniques of calming, breathing and muscle relaxation.

3. Exercise "My strong-willed composure" (Gritsevich, 2017: 348). conditions.

Purpose: the formation of skills necessary for voluntary decision-making in extreme

4. Exercise "Relieving stress with self-massage" (Gritsevich, 2017: 350).

Purpose: the formation of skills necessary for voluntary decision-making in extreme conditions.

5. Exercise "Emotions that accompany me in life" (Afanasieva, a textbook, date of application 29.06.2021). 
Time: 10 minutes

Purpose: awareness of their own mental states, work on improving emotional feelings, the formation of skills and abilities to relieve internal tension, self-regulation.

Diagnostic component:

6. Psychological diagnosis.

7. Summarizing the lesson.

Summarizing the program.

1. Exercise "My expectations and further wishes"

Purpose: analysis of experience gained during the program, establishing feedback.

Individual psychological counseling.

Purpose: to provide psychological assistance to servicemen in solving life problems.

\section{Conclusions}

The analysis of the results of the implementation of the program for the development of psychological readiness of servicemen of the Airborne Assault Forces of the Armed Forces of Ukraine to work in combat conditions "Born - to win" shows its effective results. There is a significant advantage of statistical data between the experimental and control groups on the level of psychological readiness of paratroopers and their motivational orientation to perform tasks on purpose; skills and practical skills necessary for first aid, self-regulation and selfcontrol of emotional state. The program can be used during the training of Airborne Assault Troops in the process of psychological training of military servicemen under the contract of military units of the "platoon - battalion".

\section{References}

1. Afanasieva N.E., Perelygina L.A. Theoretical and methodological foundations of socio-psychological training: a textbook. URL: http://repositsc.nuczu.edu.ua/handle/123456789/4053 (date of application 29.06.2021).

2. Jackson A. (2014). Ten secrets of love. Kiev: Sofia, 144 pg. [in Ukrainian].

3. Zoran Komar. (2017). Psychological stability of a warrior: a textbook. Kiev.184 pg. [in Ukrainian].

4. Armed Forces of Ukraine (2021). Methodical recommendations on psychological training of servicemen of the Armed Forces of Ukraine on formation of stress resistance to actions in the conditions of sharp change of a combat situation. Armed Forces of Ukraine, 64 pg. [in Ukrainian].

5. Memo to a serviceman in preparation for and in battle: a booklet / author's team of psychological crisis service. (2015). Mykolaiv, 54 pg. [in Ukrainian].

6. Psychology of behavior in war: practice. advice. Textbook / team of authors; for general ed. V.I. Osyodlo. (2014). Kiev: NUDU, 125 pg. [in Ukrainian].

7. Psychology of combat: Manual / Gritsevich T.L., Guzenko I.M., Kapinus O.S., Matsevko T.M., Romanishin A.M.; for order. A.M. Romanishin. (2017). Lviv: Astrolabia Publishing House, $352 \mathrm{pg}$. [in Ukrainian].

8. Raid of the 95th Brigade in the summer of 2014. BBC News Ukraine. URL: https://www.bbc.com/ukrainian/features-53664708 (date of application 29.06.2021) 
9. STANAG 2565 MEDSTD (Revision 1). (2019). Psychological guidance for leaders during the deployment cycle. NATO, 86 pg. [in USA].

10. Technologies of work of organizational psychologists: textbook. way. / For science. ed. L.M. Karamushki. (2005). Kiev: INCOS Company, 366 c. 37-38 pg. [in Ukrainian].

11. Sergeant Airborne Assault Troops Sergeant's Textbook (Part One). for order. Chaplygina P.V. (1975). Moscow, 271 pg. [in Russian].

12. Shlachter V.V. (2002). Man is a weapon. Moscow: Publishing house: "Respex", 50 pg. [in Russian]. 